\title{
Genetic Diversity of Vitis davidii Accessions Revealed Using Microsatellite and Sequence-related Amplified Polymorphism Markers
}

Xiu Cai Fan, Hai Sheng Sun, Ying Zhang, Jian Fu Jiang, Min Li, and Chong Huai Liu ${ }^{1}$

Zhengzhou Fruit Research Institute, Chinese Academy of Agricultural Sciences, 450009 Zhengzhou, Henan Province, People's Republic of China

Additional index words. wild thorn grapes, genetic polymorphisms, genetic relationship, molecular genetic markers

\begin{abstract}
In this study, simple sequence repeat (SSR) and sequence-related amplified polymorphism (SRAP) markers were used to analyze the genetic diversity of 48 wild Vitis davidii accessions. A total of 78 distinct alleles were amplified by 11 SSR primers, and the average allele number was 8.8 . The average observed heterozygosity $(\mathrm{Ho})$ and expected heterozygosity $(\mathrm{He})$ values were 0.785 and 0.814 , respectively. The effective allele numbers ranged from 3.92 to 9.61 . The average polymorphism information content (PIC) was 0.798. Twelve of 169 SRAP primer combinations were selected for SRAP analysis. A total of 188 bands were produced, and the average was 15.7 bands per primer combination; the average percentage of polymorphic bands was $84.0 \%$. The average PIC was 0.76 . The results of the clustering analysis based on SSR markers showed that the 48 wild $V$. davidii accessions could be classified into five main clusters and had a genetic similarity coefficient level of 0.68 . The dendrogram obtained from the SRAP data showed that 48 wild $V$. davidii accessions could be classified into five main clusters and had a genetic similarity coefficient of 0.72 . SSR and SRAP markers differentiated all accessions studied including those with a similar pedigree. We speculated on the origin of Ciputao 0941 , Ciputao 0940 ${ }^{\circ}$, and Fu'an-ci-01 using SSR markers and used both SSR and SRAP markers to resolve homonymy. The result will be valuable for further management and protection of $V$. davidii germplasm resources.
\end{abstract}

Grapevine (Vitis spp.) is one of the most important fruit crops in the world. More than 70 species of Vitis exist, which are mostly found in the temperate zones of the Northern Hemisphere. These species are distributed mostly in three regions: Europe and western Asia, North America, and eastern Asia (Alleweldt and Possingham, 1988; Mullins et al., 1992). China is one of the major gene centers of origin of the Vitis species; more than 38 Vitis species originate in China (Kong, 2004). China is a vast country with complex geographical environments that greatly differ in climate, soil, and topography. Under these conditions, there is an abundance of Vitaceae species and Vitis spp. germplasm resources. The common characteristics of the Vitis species native to China include small clusters and berries, low sugar content, high acidity, and high tannin contents (Kong, 2004). Vitis

Received for publication 22 Sept. 2017. Accepted for publication $8 \mathrm{Jan} .2018$.

This work was supported by the China Agriculture Research System (CARS-29), the Agricultural Science and Technology Innovation Program (CAAS-ASTIP-2017-ZFRI), and the Crop Resources Protection Program of China Ministry of Agriculture (2130135-34).

${ }^{1}$ Corresponding author. E-mail: liuchonghuai@, caas.cn. davidii is the only east Asiatic species that has large berries, and this species has excellent tolerance to anthracnose, ripe rot disease, and hot climate (He, 1999; Shi et al., 2002). People who live in the mountainous areas of Hunan, Anhui, Jiangxi, and Shanxi provinces usually plant this wild species in their courtyard as a table grape. In the recent years, $V$. davidii and their hybrids have been used for making wines and juice in China (Bao et al., 2010; Qin et al., 2008; Zhou et al., 2008).

Molecular genetic markers constitute one of the most powerful tools for analyzing genomes and enable the association of heritable traits with underlying genomic variation (Duran et al., 2009). SSRs, whose advantages include codominance, high allele diversity, high stability, and simple operation, have been widely used in genetic diversity analyses of grape resources (Adam-Blondon et al., 2004; Emanuelli et al., 2013; Martínez et al., 2006; Rakonjac et al., 2014; Wang et al., 2015) and in other fields. Sequence-related amplified polymorphisms constitute a polymerase chain reaction (PCR)-based marker system that targets open reading frames $(\mathrm{Li}$ and Quiros, 2001). Because of their reproducible results, high reliability, simple technology, and low cost, SRAPs have been applied to assess the genetic diversity of many fruit species (Abedian et al., 2012; Ahmad et al., 2004; Amar et al., 2011; Fan et al., 2015; Guo and Luo, 2006). Polymorphic SRAPs were abundant and demonstrated genetic diversity among closely related cultivars (Budak et al., 2004).

SSR and SRAP have also been used in genetic diversity analyses of the Chinese wild grape resources. Liu et al. (2012a) reported on the relationship of 15 Chinese wild grape species based on the 10 microsatellite markers and 12 SRAP combinations. Fan et al. (2015) assessed genetic polymorphisms of 126 individuals from five different geographical populations of wild Vitis ficifolia Bge. Zhang et al. (2012) analyzed the genetic diversity of 40 individuals of wild $V$. davidii collected from Huangshan region, Anhui province, by eight SSR markers.

In this study, we used 11 microsatellite markers and 12 SRAP combinations in 48 wild $V$. davidii accessions to investigate genetic polymorphisms and possible relationships.

\section{Materials and Methods}

Plant materials. Forty-eight accessions were collected from Hunan, Jiangxi, Zhejiang, and Anhui provinces in China. These materials were planted at the National Grape Germplasm Repository, Zhengzhou Fruit Research Institute at the Chinese Academy of Agricultural Sciences (lat. $34^{\circ} 42^{\prime} 47.52^{\prime \prime} \mathrm{N}$, long. $113^{\circ} 42^{\prime} 3.19^{\prime \prime} \mathrm{E}$ ). Information on the materials is listed in Table 1.

DNA extraction. Genomic DNA was extracted from fresh young leaves using the cetyltrimethylammonium bromide method and purified in accordance with the method reported by Liu et al. (2012b), with minor modifications. This protocol was much faster and required only two to four shoot tips. The quality and concentration of the DNA samples were checked using a BioPhotometer Plus (Eppendorf, Hamburg, Germany), and a portion of the DNA was diluted to $30-50 \mathrm{ng} \cdot \mu \mathrm{L}^{-1}$ for use in SSR and SRAP analyses. Both the stock and diluted portions were stored at $-20{ }^{\circ} \mathrm{C}$.

SSR analysis. Eleven polymorphic microsatellite loci were analyzed. Two loci (VVS2 and VVS5) were identified by Thomas and Scott (1993) and Thomas et al. (1994). Two additional loci (VVMD5 and VVMD7) were also identified in the laboratory of C.P. Meredith (Bowers et al., 1996, 1999). Other loci also included VMC4H6, VMC4C6 (Di Gaspero et al., 2000; Techera et al., 2004), UDV123 (Di Gaspero et al., 2005), VrZAG25, VrZAG62, VrZAG79 (Sefc et al., 1999), and VVIb66 (Merdinoglu et al., 2005). The SSR amplifications were performed in $20 \mu \mathrm{L}$ solutions that contained $30-50 \mathrm{ng}$ of template DNA, $0.1 \mathrm{~mm}$ dNTPs, each primer at $0.5 \mu \mathrm{M}$, $2 \mathrm{mM} \mathrm{Mg}^{2+}$, and $1 \mathrm{U}$ of Taq DNA polymerase (TaKaRa, Otsu, Japan), and the amplifications were optimized based on the methods of $\mathrm{Di}$ Gaspero et al. (2005). The amplification reaction procedure was as follows: denaturation at $94{ }^{\circ} \mathrm{C}$ for $5 \mathrm{~min} ; 35$ cycles at $94{ }^{\circ} \mathrm{C}$ for $30 \mathrm{~s}$, annealing at $50-57^{\circ} \mathrm{C}$ for $30 \mathrm{~s}$, and $72{ }^{\circ} \mathrm{C}$ for $45 \mathrm{~s}$; and a final extension at $72{ }^{\circ} \mathrm{C}$ for $7 \mathrm{~min}$. The amplification programs varied slightly only in annealing temperature because of the 
Table 1. Vitis davidii accessions used for analysis.

\begin{tabular}{|c|c|c|c|c|c|}
\hline No. & Accessions & Source & No. & Accessions & Source \\
\hline 1 & Zi luolan & Hunan province & 25 & HJ-ci-04 & Hongjiang, Hunan province \\
\hline 2 & Zi luolan & Hunan province & 26 & HJ-ci-10 & Hongjiang, Hunan province \\
\hline 3 & Fu'an-ci-01 & Fu'an, Fujian province & 27 & HJ-(HY)-ci-01 & Hongjiang, Hunan province \\
\hline 4 & LC-ci-03 & Luocheng, Guangxi province & 28 & HJ-(HY)-ci-02 & Hongjiang, Hunan province \\
\hline 5 & HT-ci-01 & Huitong, Guangxi province & 29 & HJ-(HY)-ci-03 & Hongjiang, Hunan province \\
\hline 6 & HT-ci-02 & Huitong, Guangxi province & 30 & HJ-(YY)-ci-05 & Hongjiang, Hunan province \\
\hline 7 & Gaoshan No. 1 & Jiangxi province & 31 & HJ-(TM)-ci-06 & Hongjiang, Hunan province \\
\hline 8 & Gaoshan No. 2 & Jiangxi province & 32 & HJ-(TM)-ci-07 & Hongjiang, Hunan province \\
\hline 9 & Gaoshan No. 3 & Jiangxi province & 33 & HJ-ci-09 & Hongjiang, Hunan province \\
\hline 10 & Tangwei 0942 & Yushan, Jiangxi province & 34 & HJ-ci-11 & Hongjiang, Hunan province \\
\hline 11 & Tangwei seedling 1 & Yushan, Jiangxi province & 35 & ZJ-ci-01 & Zhijiang, Hunan province \\
\hline 12 & Tangwei seedling 2 & Yushan, Jiangxi province & 36 & ZJ-ci-07 & Zhijiang, Hunan province \\
\hline 13 & WH-ci-01 & Wuhan, Hubei province & 37 & ZJ-(SX)-ci-08 & Zhijiang, Hunan province \\
\hline 14 & TMS-ci-02 & Tian mushan, Zhejiang province & 38 & ZJ-(SX)-ci-13 & Zhijiang, Hunan province \\
\hline 15 & TMS-ci-03 & Tian mushan, Zhejiang province & 39 & ZJ-(BMP)-ci-01 & Zhijiang, Hunan province \\
\hline 16 & Zhejiang-ci-01 & Zhejiang province & 40 & HH-ci (Green) & Huaihua, Hunan province \\
\hline 17 & Zhejiang-ci-03 & Zhejiang province & 41 & HH-miputao (sweet) & Huaihua, Hunan province \\
\hline 18 & Ciputao 0940ð & Unknown & 42 & HH-miputao (Green) & Huaihua, Hunan province \\
\hline 19 & Ciputao 0941우 & Unknown & 43 & HH-Jiaputao & Huaihua, Hunan province \\
\hline 20 & Black pearl & Hunan province & 44 & HN-ci-01 & Hunan province \\
\hline 21 & Xiang zhenzhu (Tongmu) & Tongmu, Hunan province & 45 & HN-ci-02 & Hunan province \\
\hline 22 & Xiang zhenzhu & Hunan province & 46 & Ciputao seedling 1 & Hunan province \\
\hline 23 & Xiang zhenzhu (Red) & Hunan province & 47 & Ciputao seedling 2 & Hunan province \\
\hline 24 & Xiang zhenzhu (Green) & Hunan province & 48 & Gaoshan mutation & Hunan province \\
\hline
\end{tabular}

different primers used. The amplification products were separated using $8 \%$ polyacrylamide gel electrophoresis at $75 \mathrm{~W}$ (Bio-Rad Electrophoresis system, Hercules, $\mathrm{CA})$ for $2 \mathrm{~h}$ and then visualized using a simplified silver staining method. The band sizes were then estimated.

SRAP analysis. The SRAP analysis was performed using 26 primers: 13 forward (Me1-13) and 13 reverse (Em1-13) SRAP primers were used, for a total of 169 primer combinations. Among all the primers screened, only 12 SRAP combinations showed high levels of polymorphism. Each $10 \mu \mathrm{L}$ PCR mixture consisted of $30-50 \mathrm{ng}$ of template DNA, $0.8 \mathrm{~mm}$ dNTPs, each primer at $1.0 \mu \mathrm{M}$, $0.9 \mathrm{~mm} \mathrm{Mg}^{2+}$, and $0.1 \mathrm{U}$ of Taq DNA polymerase (TaKaRa). The amplification reaction procedure was as follows: after denaturation at $94{ }^{\circ} \mathrm{C}$ for $5 \mathrm{~min}$, the reaction mixture was subjected to amplification for seven cycles consisting of $94{ }^{\circ} \mathrm{C}$ for $90 \mathrm{~s}, 35{ }^{\circ} \mathrm{C}$ for $75 \mathrm{~s}$, and $72{ }^{\circ} \mathrm{C}$ for $30 \mathrm{~s} ; 30$ cycles consisting of $94{ }^{\circ} \mathrm{C}$ for $60 \mathrm{~s}, 55^{\circ} \mathrm{C}$ for $60 \mathrm{~s}$, and $72^{\circ} \mathrm{C}$ for $90 \mathrm{~s}$; and a final extension at $72{ }^{\circ} \mathrm{C}$ for $5 \mathrm{~min}$.

Data analysis. The amplified bands were scored as either present [1] or absent [0]. The data were entered into a binary matrix and subsequently analyzed using NTSYSpc 2.1 software (Rohlf, 2000). Coefficients of similarity were calculated using the Dice coefficient (Sokal and Rohlf, 1962), and a cluster analysis was performed using the agglomerative technique and the unweighted pair group method with arithmetic mean (UPGMA). The PIC, microsatellite allele frequencies, the number of alleles per locus $(\mathrm{Na})$, the effective number of alleles ( $\mathrm{Ne}$ ), and the $\mathrm{Ho}$ and $\mathrm{He}$ as genetic parameters of polymorphism were calculated using POPGENE 32 software.

\section{Results and Discussion}

SSR analysis. Forty-eight $V$. davidii accessions were analyzed using 11 polymorphic
SSRs. The variability detected by each SSR locus is shown in Table 2. The total number of amplified alleles was 78,73 of these alleles $(93.6 \%)$ were polymorphic in the 48 genotypes studied. The $\mathrm{Na}$ ranged from 4 (UDV123) to 10 (VVMD5, VVMD7, VMC4C6, and VMC4H6), with an average of 8.8 alleles/locus, which is lower than the findings obtained from some Chinese wild grape accessions (Liu et al., 2012a) but is in accordance with the results of the Huangshan region accessions (Zhang et al., 2012). This indicated a lower level of genetic differentiation among $V$. davidii accessions.

In this study, the percentage of heterozygotes of the 11 loci was high, indicating the high variability present in the samples. The $H e$ values ranged from 0.726 at locus VVS2 to 0.894 at locus VrZAG79, the average value of the $H e$ is 0.814 , which was lower than that reported by Li et al. (2017) (0.839) among Chinese grape landraces. The values of $\mathrm{Ho}$ for individual loci ranged from 0.709 at locus VrZAG62 to 0.833 at locus VVIb66, with a mean of 0.785 (Table 2). The mean $\mathrm{He}$ was slightly higher than the Ho. This difference could be explained by the lack of human selection, which reduced homozygosity in grape plants (Sefc et al., 2001).

The values of PIC varied from 0.732 to 0.847 , with a mean of 0.798 . The most informative locus was VrZAG79 (0.847) and the least informative locus was VVS2 (0.732) (Table 2). The mean PIC value was higher than that reported by Zhang et al. (2012) (0.500) in wild $V$. davidii accessions in the Huangshan region. The high PIC value suggesting a high discriminating ability of the SSR markers for the grape.

SRAP analysis. Twelve pairs of SRAP primer combinations were selected for their ability to produce clear and repeated polymorphic and unambiguous bands among the varieties (Table 3 ). As the data in Table 3 indicate, a total of 188 bands were obtained
Table 2. Number of alleles $(\mathrm{Na})$, effective number of alleles $(\mathrm{Ne})$, observed $(\mathrm{Ho})$ and expected $(\mathrm{He})$ heterozygosity, and polymorphic information content (PIC) of the 11 simple sequence repeat loci analyzed.

\begin{tabular}{lrccccc}
\hline Locus & Chr. & $\mathrm{Na}$ & $\mathrm{Ne}$ & $\mathrm{Ho}$ & $\mathrm{He}$ & $\mathrm{PIC}$ \\
\hline UDV123 & 14 & 4 & 3.92 & 0.804 & 0.813 & 0.810 \\
VrZAG25 & 10 & 7 & 6.51 & 0.813 & 0.887 & 0.843 \\
VrZAG62 & 7 & 8 & 6.08 & 0.709 & 0.791 & 0.763 \\
VrZAG79 & 5 & 7 & 6.53 & 0.811 & 0.894 & 0.847 \\
VVS2 & 11 & 8 & 7.28 & 0.782 & 0.726 & 0.732 \\
VVS5 & 6 & 7 & 6.63 & 0.812 & 0.833 & 0.801 \\
VVIb66 & 8 & 7 & 6.34 & 0.833 & 0.767 & 0.798 \\
VVMD5 & 16 & 10 & 8.89 & 0.813 & 0.831 & 0.803 \\
VVMD7 & 7 & 10 & 8.62 & 0.813 & 0.834 & 0.821 \\
VMC4C6 & 5 & 10 & 9.20 & 0.712 & 0.791 & 0.779 \\
VMC4H6 & 9 & 10 & 9.61 & 0.735 & 0.782 & 0.777 \\
Mean & & 8.8 & 7.24 & 0.785 & 0.814 & 0.798 \\
\hline
\end{tabular}

Table 3. Details of sequence-related amplified polymorphism primers in this study.

\begin{tabular}{lccrc}
\hline Primer combinations & Size (bp) & TNB & NPB & PIC \\
\hline Me2/Em8 & $50-700$ & 11 & 8 & 0.71 \\
Me3/Em13 & $100-900$ & 20 & 17 & 0.74 \\
Me4/Em6 & $100-1,000$ & 22 & 21 & 0.80 \\
Me4/Em13 & $50-500$ & 13 & 12 & 0.78 \\
Me5/Em7 & $100-1,000$ & 14 & 14 & 0.82 \\
Me6/Em7 & $100-800$ & 12 & 8 & 0.67 \\
Me8/Em13 & $500-1,300$ & 16 & 13 & 0.83 \\
Me9/Em7 & $50-1,500$ & 24 & 20 & 0.73 \\
Me10/Em6 & $100-1,000$ & 22 & 19 & 0.75 \\
Me11/Em6 & $110-900$ & 16 & 12 & 0.76 \\
Me11/Em8 & $100-1,000$ & 11 & 8 & 0.69 \\
Me13/Em7 & $100-500$ & 7 & 6 & 0.81 \\
\hline
\end{tabular}

$\mathrm{NPB}=$ number of polymorphic bands; PIC $=$ polymorphism information content; TNB = number of total bands.

using the 12 primers. Of the 188 bands, 158 were highly polymorphic $(84.0 \%$ polymorphic) and ranged from 50 to $1500 \mathrm{bp}$. The number of amplicons scored per primer combination ranged from $7(\mathrm{Me} 13 / \mathrm{Em} 7)$ to $24(\mathrm{Me} 9 / \mathrm{Em} 7)$, and the average was 15.7 bands per primer combination. Of these bands, $66.7 \%(\mathrm{Me} 6 / \mathrm{Em} 7)$ to $100 \%(\mathrm{Me} 5 / \mathrm{Em} 7)$ 
were polymorphic among the 48 accessions, and the average of the percentage of polymorphic bands was $84.0 \%$, which is higher than that of the cultivated varieties and wild Vitis species (Guo et al., 2012), but less than that among Chinese wild Vitis species (Liu et al., 2012a). The PIC values for the 12 primer combinations ranged from 0.67 (Me6/ Em7) to 0.83 (Me8/Em13) and had a mean of 0.76 (Table 3 ). Seven of the 12 markers were highly polymorphic and had a PIC value equal to or greater than 0.75 . The PIC results for each marker confirmed its ability to show differences between the samples analyzed in this study.

Cluster analysis. The genetic similarity data obtained from the SSRs and SRAPs were used for cluster analysis. The dendrograms showing the relationships among $48 \mathrm{~V}$. davidii accessions based on the SSR and SRAP data are shown in Figs. 1 and 2, respectively.

The dendrogram obtained from the SSR analysis is shown in Fig. 1. Genetic similarities coefficient among all accessions ranged from 0.63 to 0.99 , with a mean similarity of 0.81 . The SSR markers used revealed lower genetic distances between most accessions, indicating that the genetic variation was small and the genetic differentiation was low among the $V$. davidii accessions, which is in accordance with the results of $V$. ficifolia accessions (Wang et al., 2008).

The UPGMA clustering algorithm grouped the 48 accessions into five main clusters at the genetic similarity coefficient of 0.68 . The first cluster contained three accessions from Hunan province, including two accessions named 'Ziluolan' and 'Black Pearl'. The second cluster contained 14 accessions: Fu'an-ci-01 from Fujian province; 12 accessions from Hongjiang, Hunan province [HJ-ci04, HJ-ci-10, HJ-(HY)-ci-03, HJ-(YC)-ci-05, HJ-(TM) ci-07, HJ-(HY) ci-01, HJ-ci-11, HJ(HY) ci-02, HJ-(TM) ci-06, HJ-ci-09, HN-ci01 , and HN-ci-02]; and one unknown source accession (Ciputao 0941). With a similarity coefficient of 0.72 , the second cluster could be divided into three subgroups. Subgroup one included Fu'an-ci-01 from Fujian province and 11 accessions from Hongjiang, Hunan province. Subgroup two included only Ciputao 0941, and subgroup three included two accessions, HN-ci-01 and HN-ci-02. The third cluster contained 23 accessions, including three accessions from Guangxi province (LC-ci-03, HT-ci-02, and HT-ci-01), six accessions from Jiangxi province (Gaoshan No. 1, Gaoshan No. 3, Gaoshan No. 2, Tangwei 0942, Tangwei seedling 1, and Tangwei seedling 2), four accessions from Zhejiang province (TMS-ci-02, TMS-ci-03, Zhejiang-ci-01, and Zhejiang-ci-03), and 10 accessions from Hunan province [4 accessions with name 'Xiangzhenzhu' and HH-ci (Green), HH miputao (Sweet), HH Jiaputao, HH miputao (Green), Ciputao Seedling 2, and Gaoshan mutation]. The fourth cluster contained only Ciputao Seedling 1. The fifth cluster contained seven accessions: one unknown source accession (Ciputao 0940今); one accession from Wuhan, Hubei province (WH-ci-01); and all five accessions from Zhijiang, Hunan province [ZJ-ci-01, ZJ-ci-07, ZJ-ci-01, ZJ(SX)-ci-13, and ZJ-(SX)-ci-08]. The SSR analysis results showed almost accessions from same geographical regions or the surrounding area grouped together. Breeding origin could explain the tendency that genotypes developed from the same region group together. Similar results were obtained by Liu et al. (2012a).

On the basis of the data in Fig. 1, Ciputao 0941, which was unknown source; Fu'an-ci01 from Fujian province; and 12 accessions from Hongjiang, Hunan province were classified into the same cluster, and the genetic similarity coefficient between Fu'an-ci-01 and HJ-ci-04 reached 0.97 , which suggests that their origin may be in Hongjiang or in the surrounding area. Ciputao 0940 and five accessions from Zhijiang, Hunan province were classified into the same cluster and had a genetic similarity coefficient of 0.70 , which suggests that the origin of these accessions may be in Zhijiang or in the surrounding area. However, because of the limited number of samples in the test, we need to expand the scope of dense sampling in future studies. Two accessions with name of 'Ziluolan' from Hunan province showed very different DNA profiles. Four accessions from Hunan province with name of 'Xiangzhenzhu' also showed very different DNA profiles.

The dendrogram obtained from the SRAP data is shown in Fig. 2. All the accessions were classified into six main clusters at the genetic similarity coefficient of 0.72 . The first cluster contained three accessions from Hunan province, including 'Ziluolan', HJ-ci04 and 'Xiangzhenzhu' (Red). The second cluster contained 20 accessions, including one accession from Fujian province (Fu'anci-01), two accessions from Zhejiang province (Zhejiang-ci-01 and TMS-ci-02), two

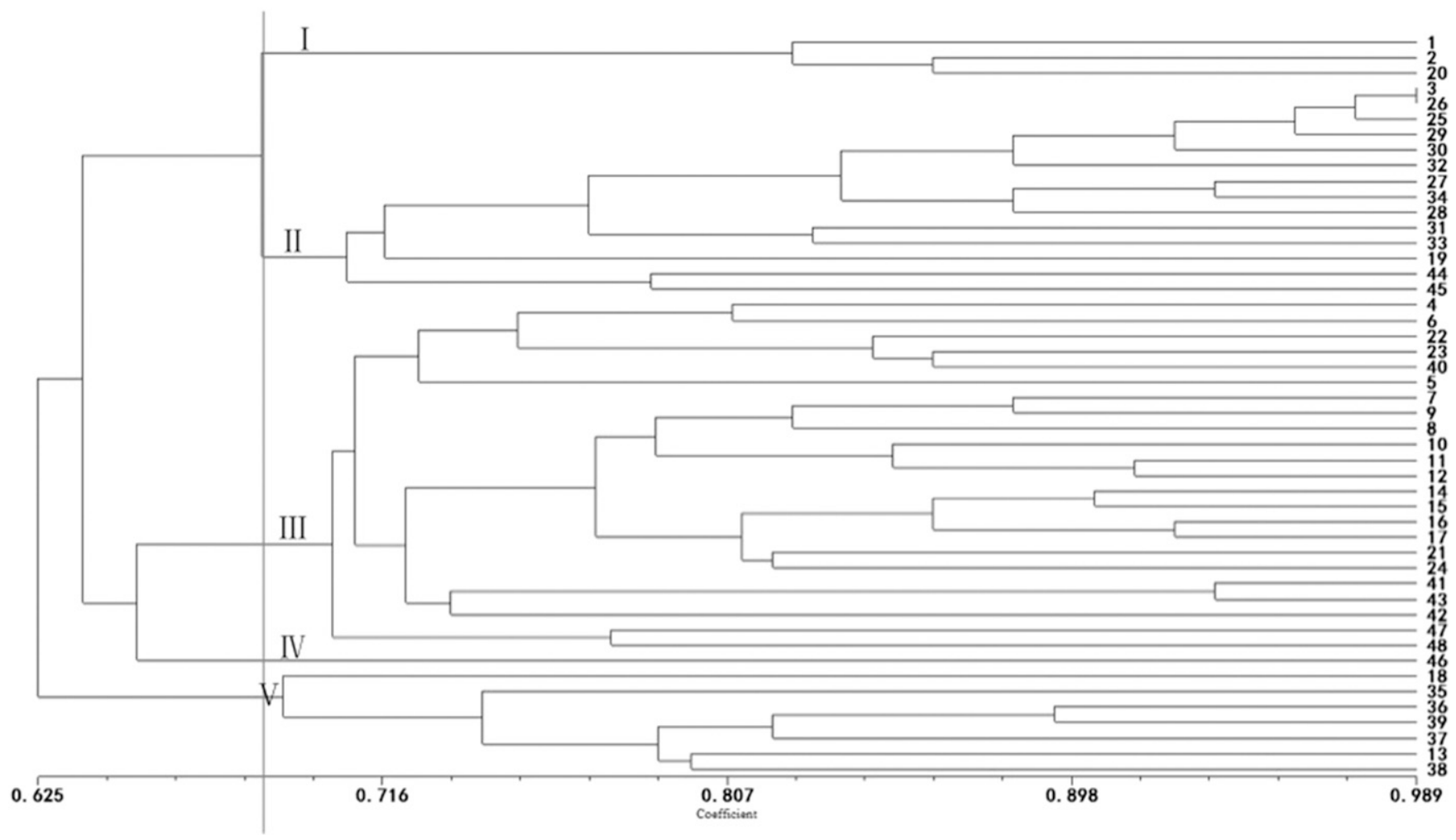

Fig. 1. Dendrogram of genetic relationships of the Vitis davidii accessions based on simple sequence repeat analysis. 


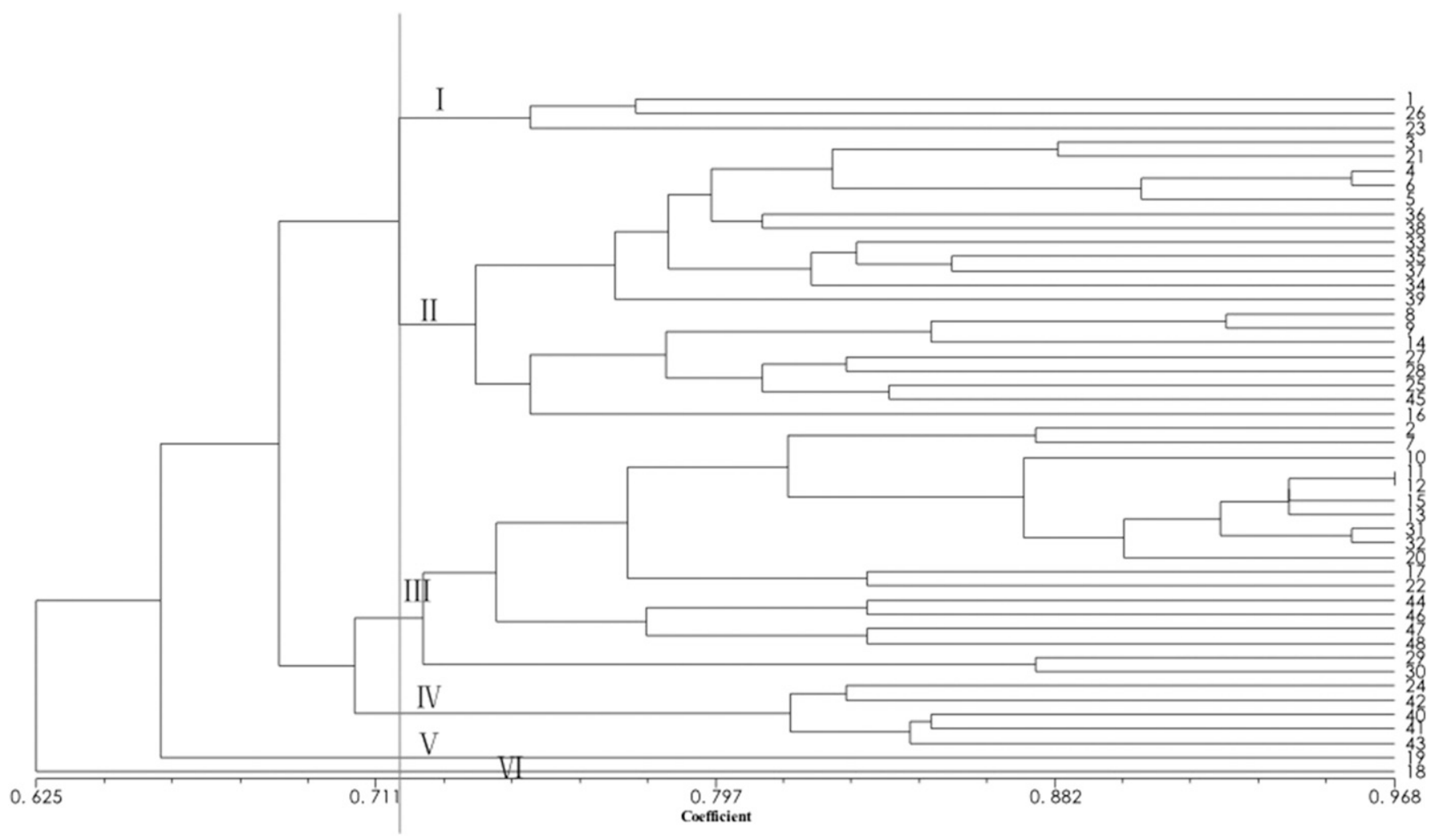

Fig. 2. Dendrogram of genetic relationships of the Vitis davidii accessions based on sequence-related amplified polymorphism analysis.

accessions from Jiangxi province (Gaoshan No. 2 and Gaoshan No. 3), and 15 accessions from Hunan province ['Xiangzhenzhu' (TM), LC-ci-03, HT-ci-02, HT-ci-01, ZJci-07, ZJ-(SX)-ci-08, HJ-ci-09, ZJ-ci-01, ZJ-(SX)-ci-13, HJ-ci-11, ZJ-(BMP)-ci-01, HJ-(HY)-ci-01, HJ-(HY)-ci-02, HJ-ci-10, and HN-ci-02]. The third cluster contained 18 accessions, including one accession from Hubei province (WH-ci-01), two accessions from Zhejiang province (TMS-ci03 and Zhejiang-ci-03), four accessions from Jiangxi province (Gaoshan No. 1, Tangwei 0942, Tangwei seedling 1 , and Tangwei seedling 2), and 11 accessions from Hunan province ['Ziluolan', HJ(TM)-ci-06, HJ-(TM)-ci-07, 'Black Pearl', 'Xiangzhenzhu', HN-ci-01, Ciputao seedling 1, Ciputao seedling 2, Gaoshan mutation, HJ-(HY)-ci-03, and HJ-(YC)-ci-05]. The fourth cluster contained five accessions, including 'Xiangzhenzhu' (Green), HH-ci (Green), HH miputao (Sweet), HH Jiaputao, and HH miputao (Green). The fifth cluster contained only Ciputao 0941웅 and the sixth cluster contained only Ciputao 0940 0 . The clustering results from the SRAPs showed two accessions with the name of 'Ziluolan' from Hunan province, which showed very different DNA profiles, and four accessions with name of 'Xiangzhenzhu' from Hunan province, which also showed very different DNA profiles.

\section{Conclusions}

The present study highlights the usage of SSR and SRAP techniques for studying genetic diversity at the DNA level in 48 wild $V$. davidii accessions to investigate genetic polymorphisms and relationships among accessions. The results showed that, the number of loci that present allelic variation and the genetic diversity coefficients labeled by SSRs and SRAPs both revealed the abundant genetic diversity of wild $V$. davidii accessions. The SSR analysis results showed almost accessions from same geographical regions or the surrounding area grouped together, and we speculated on the origin of Ciputao 0941, Ciputao 0940今, and Fu'anci-01 using SSR markers. Both SSR and SRAP markers can be used to identify homonyms. The result will be valuable for further management and protection of wild $V$. davidii germplasm resources.

\section{Literature Cited}

Abedian, M., M. Talebi, H.R. Golmohammdi, and B.E. Sayed-Tabatabaei. 2012. Genetic diversity and population structure of mahaleb cherry (Prunus mahaleb L.) and sweet cherry (Prunus avium L.) using SRAP markers. Biochem. Syst. Ecol. 40:112-117.

Adam-Blondon, A.F., C. Roux, D. Claux, G. Butterlin, D. Merdinoglu, and P. This. 2004. Mapping 245 SSR markers on the Vitis vinifera genome: A tool for grape genetics. Theor. Appl. Genet. 109:1017-1027.

Ahmad, R., D. Potter, and S.M. Southwick. 2004. Genotyping of peach and nectarine cultivars with SSR and SRAP molecular markers. J. Amer. Soc. Hort. Sci. 129:204-210.

Alleweldt, G. and J.V. Possingham. 1988. Progress in grapevine breeding. Theor. Appl. Genet. 75:669-673.

Amar, M.H., M.K. Biswas, Z. Zhang, and W.W. Guo. 2011. Exploitation of SSR, SRAP and
CAPS-SNP markers for genetic diversity of Citrus germplasm collection. Scientia Hort. 128:220-227.

Bao, R.F., D. Qin, M. Tang, L. Deng, and J. Yang. 2010. Study on the flavoring compositions of Vitis davidii Foëx fruit wine. Making Sci. Technol. 188:53-56 (in Chinese).

Bowers, J.E., G.S. Dangl, and C.P. Meredith. 1999. Development and characterization of additional microsatellite DNA markers for grape. Amer. J. Enol. Viticult. 50:243-246.

Bowers, J.E., G.S. Dangl, R. Vignani, and C.P. Meredith. 1996. Isolation and characterization of new polymorphic simple sequence repeat loci in grape (Vitis vinifera L.). Genome 39:628-633.

Budak, H., R.C. Shearman, I. Parmaksiz, and I. Dweikat. 2004. Comparative analysis of seeded and vegetative biotype buffalograsses based on phylogenetic relationship using ISSRs, SSRs, RAPDs, and SRAPs. Theor. Appl. Genet. 109:280-288.

Di Gaspero, G., G. Cipriani, M.T. Marrazzo, D. Andreetta, M.J.P. Castro, E. Peterlunger, and R. Testolin. 2005. Isolation of (AC)nmicrosatellites in Vitis vinifera $\mathrm{L}$. and analysis of genetic background in grapevines under marker assisted selection. Mol. Breeding 15:11-20.

Di Gaspero, G., E. Peterlunger, R. Testolin, K.J. Edwards, and G. Cipriani. 2000. Conservation of microsatellite loci within the genus Vitis. Theor. Appl. Genet. 101:301-308.

Duran, C., N. Appleby, D. Edwards, and J. Batley. 2009. Molecular genetic markers: Discovery, applications, data storage and visualisation. Curr. Bioinform. 4:16-27.

Emanuelli, F., S. Lorenzi, L. Grzeskowiak, V. Catalano, M. Stefanini, M. Troggio, S Myles, J.M. Martinez-Zapater, E. Zyprian, F.M. Moreira, and M.S. Grando. 2013. Genetic diversity and population structure 
assessed by SSR and SNP markers in a large germplasm collection of grape. BMC Plant Biol. 13:39.

Fan, X., J. Jiang, Y. Zhang, H. Sun, J. Jiao, and C. Liu. 2015. Genetic diversity assessment of Vitis ficifolia Bge. populations from Henan province of China by SRAP markers. Biotechnol. Biotechnol. Equip. 29:15-20.

Guo, D.L. and Z.R. Luo. 2006. Genetic relationships of some PCNA persimmons (Diospyros kaki Thunb.) from China and Japan revealed by SRAP analysis. Genet. Resources Crop Evol. 53:1597-1603.

Guo, D., J. Zhang, C. Liu, G. Zhang, M. Li, and Q. Zhang. 2012. Genetic variability and relationships between and within grape cultivated varieties and wild species based on SRAP markers. Tree Genet. Genomes 8:789-800.

He, P.C. 1999. Chinese ampelology. China Agr. Press, Beijing, China (in Chinese).

Kong, Q.S. 2004. Flora of Chinese grapes. China Agr. Technol. Press, Beijing, China (in Chinese).

Li, B.B., J.F. Jiang, X.C. Fan, Y. Zhang, H.S. Sun, G.H. Zhang, and C.H. Liu. 2017. Molecular characterization of Chinese grape landraces (Vitis L.) using microsatellite DNA markers. HortScience 52:1-8.

Li, G. and C.F. Quiros. 2001. Sequence-related amplified polymorphism (SRAP), a new marker system based on a simple PCR reaction: Its application to mapping and gene tagging in Brassica. Theor. Appl. Genet. 103:455-461.

Liu, C., X. Fan, J. Jiang, D. Guo, H. Sun, Y. Zhang, and J. Feng. 2012a. Genetic diversity of Chinese wild grape species by SSR and SRAP markers. Biotechnol. Biotechnol. Equip. 26:2899-2903.

Liu, K.Y., F. XV, X.H. Shi, X.H. Zhong, G.S. Yang, and J.J. Ni. 2012b. Relationship analysis for Vitis davidii Foëx with SRAP molecular markers. J. Hunan. Agr. Univ. 38:607-611 (in Chinese).
Martínez, L.E., P.F. Cavagnaro, R.W. Masuelli, and M. Zúñiga. 2006. SSR-based assessment of genetic diversity in South American Vitis vinifera varieties. Plant Sci. 170:1036-1044.

Merdinoglu, D., G. Butterlin, L. Bevilacqua, V. Chiquet, A.F. Adam-Blondon, and S. Decroocq. 2005. Development and characterization of a large set of microsatellite markers in grapevine (Vitis vinifera L.) suitable for multiplex PCR. Mol. Breeding 15:349-366.

Mullins, M.G., A. Bouquet, and L.E. Williams. 1992. Biology of the grapevine. Cambridge Univ. Press, New York, NY.

Qin, D., X.Y. Xiong, X.H. Shi, and Y.P. Hu. 2008. Research on production technology for brier grape juice. Food Sci. Technol. 1:50-52 (in Chinese).

Rakonjac, V., N. Korac, S. Todic, M. Medic, Z. Beslic, I. Kuljancic, D. Ivanisevic, and $\mathrm{M}$ Popov. 2014. Genetic diversity of a Serbian grapevine germplasm collection based on morphoagronomic characteristics. Genetika 46:719-730.

Rohlf, F.J. 2000. Ntsys-pc: Numerical taxonomy and multivariate analysis system, Version 2.1. Exeter Software, State Univ. New York, Setauket, NY.

Sefc, K.M., F. Lefort, M.S. Grando, K.D. Scott, H. Steinkellner, and M.R. Thomas. 2001. Microsatellite markers for grapevine: A state of the art, p. 433-463. In: K.A. Roubelakis-Angelakis (ed.). Molecular biology \& biotechnology of the grapevine. Springer Netherlands, Dordrecht, The Netherlands.

Sefc, K.M., F. Regner, E. Turetschek, J. Glossl, and H. Steinkellner. 1999. Identification of microsatellite sequences in Vitis riparia and their applicability for genotyping of different Vitis species. Genome 42:367-373.

Shi, X.H., Y.Z. Wang, Z.Y. Chen, G.S. Yang, K.Y. Liu, X.H. Zhong, J.Y. Chen, and G.Y. Long.
2002. The preliminary study on the botanical character and the disease resistance of Hunan brier grape. Sino-Overseas Grapevine Wine 2:22-24 (in Chinese).

Sokal, R.R. and F.J. Rohlf. 1962. The comparison of dendrograms by objective methods. Taxon $11: 33-40$.

Techera, A.G., S. Jubany, I. Ponce de León, E. Boido, E. Dellacassa, F.M. Carrau, P. Hinrichsen, and C. Gaggero. 2004. Molecular diversity within clones of cv. Tannat (Vitis vinifera). Vitis 43:179-185.

Thomas, M.R., P. Cain, and N.S. Scott. 1994. DNA typing of grapevines: A universal methodology and database for describing cultivars and evaluating genetic relatedness. Plant Mol. Biol. 25:939-949.

Thomas, M.R. and N.S. Scott. 1993. Microsatellite repeats in grapevine reveal DNA polymorphisms when analysed as sequence-tagged sites (STSs). Theor. Appl. Genet. 86:985-990.

Wang, J., C.H. Liu, X.C. Fan, H.S. Sun, and D. Dong. 2008. Study on the biodiversity of the morphology and polymorphism based on SSR markers for Vitis ficifolia native to Henan province in China. J. Fruit Sci. 25:496-500 (in Chinese).

Wang, L., J. Zhang, L. Liu, L. Zhang, L. Wei, and D. Hu. 2015. Genetic diversity of grape germplasm as revealed by microsatellite (SSR) markers. Afr. J. Biotechnol. 14:990-998.

Zhang, M., C.L. Lian, M. Yu, S.H. Wang, and J.M. Tao. 2012. Genetic diversity analysis of wild in Huangshan region, Anhui province based on SSR molecular markers. Acta Agr. Jiangxi 24:9-12 (in Chinese).

Zhou, J., X.H. Shi, D. Qin, X.Y. Xiong, G.S. Yang, and Y. Wei. 2008. Study on the wine making with grapes of $V$. davidii Foex in Hunan. Sinooverseas Grapevine \& Wine 3:14-16, 20 (in Chinese). 